\title{
Urethral mobilization and advancement technique in distal types of hypospadias: short-term local experience
}

\author{
Obay Abdul Aziz Edan(D)
}

\begin{abstract}
Background: A prospective study was conducted on 65 cases with distal hypospadias operated using the urethral mobilization technique between July 2017 and December 2019. Patients with proximal hypospadias and those with distal hypospadias, but with a hypoplastic urethra, were excluded from the study. In this technique, the urethral tube was mobilized proximally in a ratio of 3-4:1 (the ratio of mobilized urethral length to the initial distance between the native meatus and the tip of the glans) then positioned distally after creating wide glans wings. The aim of this study was to assess the outcome of the urethral mobilization technique in distal hypospadias in our center.

Results: The age of patients was ranged 9 months to 7 years old (mean 37.5 months); 17 (26\%) cases were already circumcised. During the postoperative follow-up, 62 (95.4\%) patients had a good caliber neomeatus with a good and straight urinary stream; the remaining $3(4.6 \%)$ cases developed meatal stenosis which responded well to urethral dilatation. One (1.5\%) patient had a minor retraction of neomeatus but remained within the glans and not requiring further intervention. Four (6\%) cases developed minor hematoma which was resolved on conservative measures. Six (9.2\%) patients developed minor wound infection which was treated with daily dressing and antibiotic coverage.

Conclusion: The urethral mobilization technique is a good choice for repairing distal hypospadias especially for boys who are previously circumcised as the preputial flap is not required in this technique. It provides good cosmetic and functional results, with a fewer complication rate.
\end{abstract}

Keywords: Urethral mobilization, Distal, Hypospadias

\section{Background}

Hypospadias is a congenital anomaly of the penile urethra representing a ventrally placed urethral meatus proximal to the glans tip. It results from arrest in normal embryologic development of the ventral penile tissue including the urethra and the foreskin [1]. The most common type of hypospadias is the distal variant, which include glanular, coronal, and distal penile shaft hypospadias. Hypospadias may be associated with other penile defects like chordee which represents a ventral

\footnotetext{
Correspondence: obayabdedaan@uomosul.edu.iq

Department of Surgery, College of Medicine, University of Mosul, Mosul, Iraq
}

bending of the penile shaft of varying degrees, and it is usually associated with the proximal variant of hypospadias (i.e., proximal shaft, penoscrotal, scrotal, and perineal hypospadias). Penile torsion is another associated defect that should be corrected during surgical treatment $[1,2]$.

\section{Embryology and anatomy}

Normal penile development occurs between the 6th and 14th weeks of gestation. The first stage of development, which is not dependent on a particular hormone, occurs in both males and females, and it starts around the 6th week of gestation when the genital tubercle is developed
Springer Open (c) The Author(s). 2021 Open Access This article is licensed under a Creative Commons Attribution 4.0 International License, which permits use, sharing, adaptation, distribution and reproduction in any medium or format, as long as you give appropriate credit to the original author(s) and the source, provide a link to the Creative Commons licence, and indicate if changes were made. The images or other third party material in this article are included in the article's Creative Commons licence, unless indicated otherwise in a credit line to the material. If material is not included in the article's Creative Commons licence and your intended use is not permitted by statutory regulation or exceeds the permitted use, you will need to obtain permission directly from the copyright holder. To view a copy of this licence, visit http://creativecommons.org/licenses/by/4.0/. 
in front of the urogenital sinus [3]. The two genital folds develop caudal to the genital tubercle, and the urethral plate develops between them. The human chorionic gonadotropin (HCG) that is excreted from the placenta stimulates the fetal testicular tissue to produce testosterone in the 8th week of gestation. Under testosterone effect, the inner genital folds fuse medially to form a tube connected with the urogenital sinus and runs distally to the base of the glans. The development of the penile urethra is completed by the end of the first trimester [4].

The glanular urethra is the last part of the urethra to develop, and for this reason, the distal types of hypospadias are more predominant $[5,6]$.

Any arrest in the development of the urethra may leave the meatus to be located ventrally at any point proximal to the normal meatal position. Typically, this leads to arrest in developing other structures that form the penis, leading to the development of the chordee and hooded prepuce $[6,7]$.

\section{Aim of the study}

The aim of the study is to assess the outcome of the urethral mobilization technique in distal hypospadias in our center.

\section{Methods}

A prospective study was applied on patients with distal hypospadias (glanular, coronal, and subcoronal) operated using the urethral mobilization technique in a pediatric surgical center in Mosul city between July 2017 and December 2019. Patient's data including age, meatal location, presence of chordee, penile torsion, preputal condition, and postoperative complications were recorded (Tables 1 and 2).

Patients with a proximal variant of hypospadias (midshaft, penoscrotal, and scrotal variant) and patients with

Table 1 Patients data

\begin{tabular}{llll}
\hline & & Number & Percentage \\
\hline Age & Nine months to 1 year & 7 & $10.8 \%$ \\
& One to 3 years & 36 & $55.4 \%$ \\
Meatal position & Three to 7 years & 22 & $33.8 \%$ \\
& Glanular & 18 & $27.7 \%$ \\
& Coronal & 35 & $53.8 \%$ \\
& Subcoronal & 12 & $18.5 \%$ \\
Chordee & Present (mild) & 4 & $6 \%$ \\
& Absent & 61 & $94 \%$ \\
Penile torsion & Present (mild $<40^{\circ}$ ) & 2 & $3 \%$ \\
& Absent & 63 & $97 \%$ \\
Circumcision & Circumcised & 17 & $26 \%$ \\
& Uncircumcised & 48 & $74 \%$ \\
\hline
\end{tabular}

Table 2 Postoperative complications

\begin{tabular}{lll}
\hline Complication & Number & Percentage \\
\hline Hematoma & 4 & $6 \%$ \\
Wound infection & 6 & $9.2 \%$ \\
Meatal retraction & 1 & $1.5 \%$ \\
Meatal stenosis & 3 & $4.6 \%$ \\
Urethral fistula & 0 & 0 \\
\hline
\end{tabular}

distal type but with a hypolpastic urethra were excluded from this study.

\section{Surgical procedure}

At the beginning, the gap between the native meatus and the tip of the glans was measured (Figs. 1a and 2a). A traction 3/0 silk suture was fixed on the glans, then a soft tube sized 8 French was inserted into the bladder as a stent; a circumferential subcoronal incision was done leaving about $1 \mathrm{~cm}$ width of mucosa dorsally and extend ventrally just proximal to the hypospadias meatus, then penile degloving was done releasing any tethered tissue causing chordee, and after that, a tourniquet was applied, then another circular incision was done around the urethral meatus, and by using a fine scissor, the urethra was mobilized from its bed on the glans and dissection continues proximally till we reach a ratio of 3-4: 1 (which represent the ratio of the mobilized urethral length and the distance between the native meatus and the tip of glans) (Fig. 1b), then a midline incision done on the ventral surface of the glans which deepen enough to create the bed for the mobilized urethra with a wide glans wings. A ventral slit incision was done in the stenosed hypospadias meatus; after that, the urethra was fixed to the glans tip by 5 circumferential stitches using 6/0 Vicryl suture materials to make the neomeatus, and the glans wings were then closed by 2 to 3 interrupted stiches using 5/0 Vicryl suture material.

After that, the tourniquet was released, and the urethral stent was secured by the traction suture, and finally, circumcision was done (Figs. 1c and 2b).

A compressive dressing was applied. Intravenous antibiotics using ceftriaxone were given at the time of induction of anesthesia and continued for 3 days postoperatively, then changed to the oral route; adequate analgesia was also given.

On day 5 postoperatively, the stent was removed in all patients except in 6 cases who developed wound infection in which the stent was left for two additional days. Urethral calibration was done 14days after catheter removal by using an 8 -French urethral dilator.

\section{Follow-up}

These patients were followed up 3 days, 5 days, 3 weeks, 3 months, and 6 months postoperatively. During the 


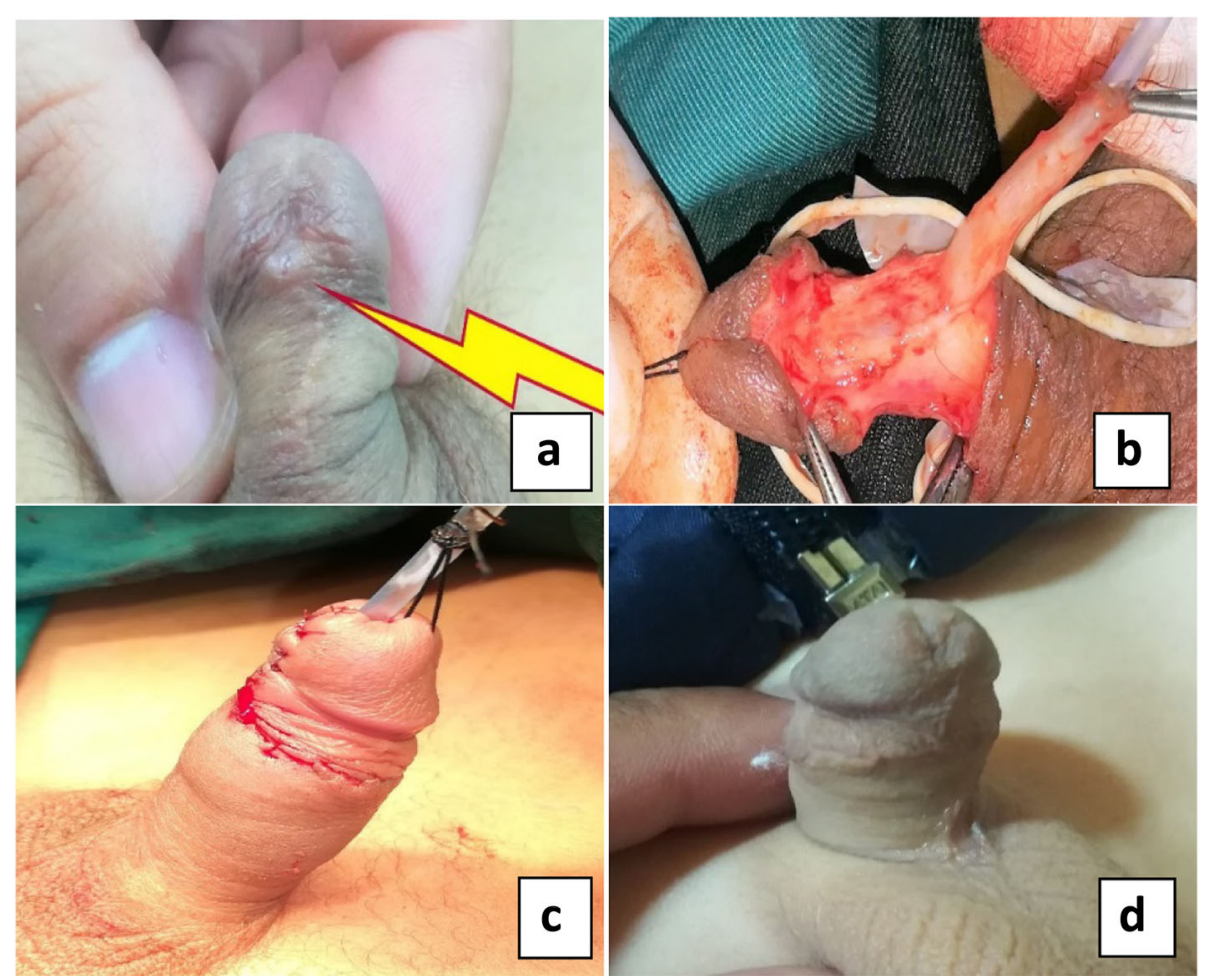

Fig. 1 a Circumcised hypospadias (preoperative). b after urethral mobilization. $\mathbf{c}$ at the end of surgery. $\mathbf{d}$ three months postoperatively

follow-up period, any evidence of wound infection, wound dehiscence, hematoma, meatal retraction, and meatal stenosis were recorded, in addition to the assessment of urinary stream and the final cosmetic outcome.

\section{Results}

The age of these 65 children was between 9 months and 7 years; among them, 35 (53.8\%) cases have coronal, 18 (27.7\%) cases have glanular, and $12(18.4 \%)$ cases have subcoronal hypospadias.

Mild chordee was present in $4(6 \%)$ patients, which was corrected by penile degloving during the main procedure. Mild penile torsion $\left(<40^{\circ}\right)$ was found in $2(3 \%)$ patients, which was also corrected by penile degloving and circumcision. Seventeen (26\%) patients were already circumcised at the time of presentation (Table 1). The operative time was ranging between 45 and $60 \mathrm{~min}$ with an average of $52.5 \mathrm{~min}$. During postoperative follow-up, 4 (6\%) patients developed a minor hematoma, which resolved spontaneously. Six (9.2\%) patients developed minor wound infection, who were treated with daily dressing and antibiotic coverage; here, the urethral stent was kept for two additional days. At the time of urethral calibration, meatal stenosis was evident in 3 (4.6\%) patients, who were treated successfully by a weekly dilatation for 3 weeks. Meatal retraction developed in one $(1.5 \%)$ patient, but it remained within the limit of the glans and does not require any further intervention. None of the patients had developed urethral fistula nor glans dehiscence (Table 2).

Regarding functional results, all of these patients experienced a straight and good urine stream (Fig. 2d), except for those three patients who developed meatal stenosis whose urine stream improved after urethral dilatation.

Regarding cosmetic results, all of these patients (except one case with meatal retraction) had a glans with a normal conical appearance with orthotopic slit-like meatus and cosmetic skin coverage (Figs. 1d and 2c).

\section{Discussion}

The urethral mobilization technique was first introduced in 1898 by Beck [8]. At that time, the overall outcome of this operative technique was not promising as the incidence of chordee that developed postoperatively was high due to an insufficient length of the mobilized urethra $[8,9]$. After that, many articles in the literature described several techniques and modifications [10-12]. In general, the length of the urethra that should be mobilized depends on the initial distance between the native meatus and the glans tip, and in our study, we did urethral mobilization in a ratio of 3-4:1 which was necessary to avoid postoperative chordee and meatal retraction.

The main obstacles of this procedure were meatal stenosis [13], and in our patients, we overcome meatal 

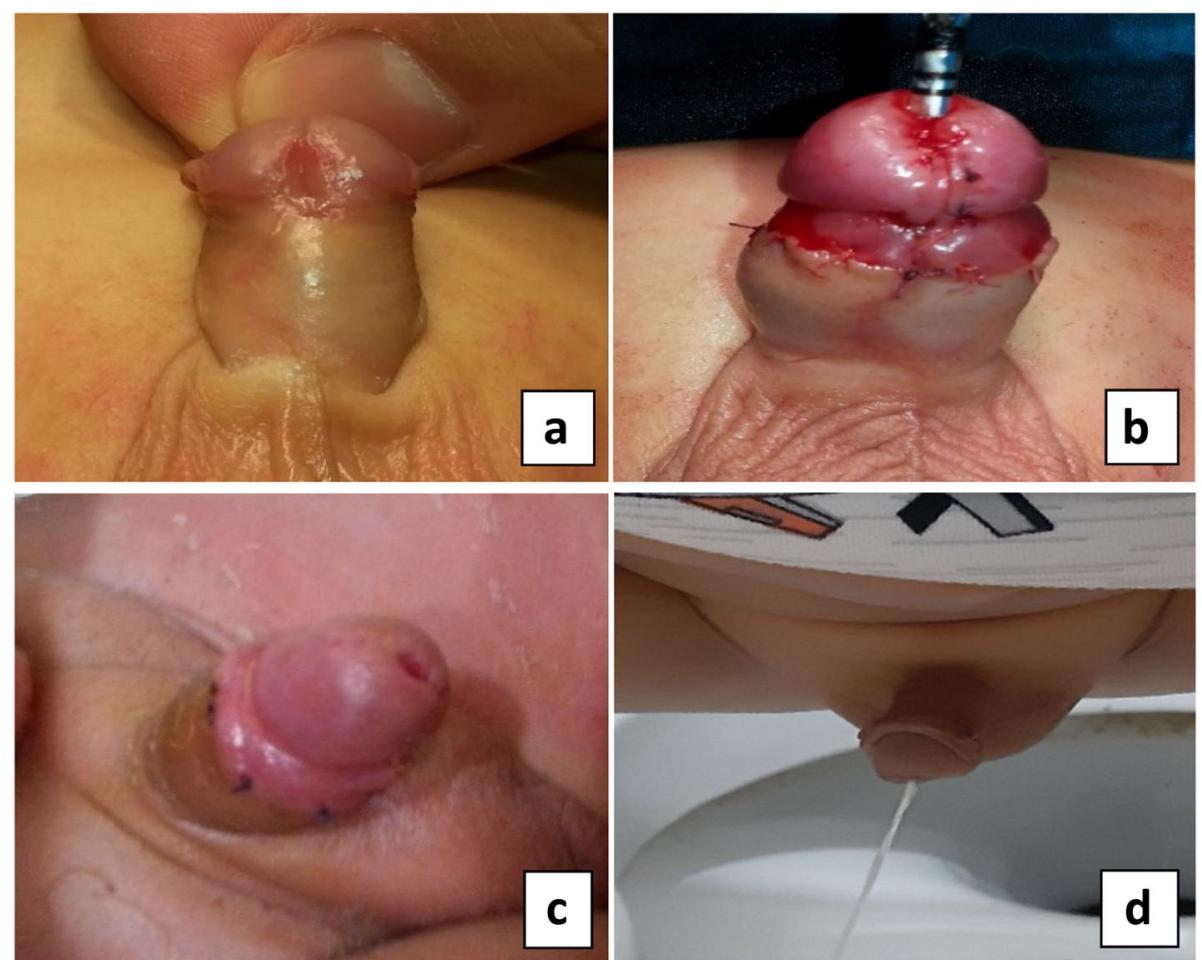

Fig. $\mathbf{2}$ a Uncircumcised subcoronal hypospadias (preoperative). $\mathbf{b}$ at the end of surgery. c three weeks postoperatively. $\mathbf{d}$ urinary stream postoperatively

stenosis by doing a ventral slit in the stenosed native meatus after mobilization with the creation of wide glans wings. We also excluded patients with a hypoplastic urethra to avoid inadvertent urethral injury during dissection. Anatomically, there is a rich urethral blood supply that comes from the terminal branch of the dorsal penile artery and the urethral branch of the internal pudendal artery; thus, the risk of urethral devascularization and ischemia is unlikely $[14,15]$.

In our study, 65 patients with distal hypospadias were operated using this technique. The age of these cases was ranging between 9 months and 7 years, with a median of 37.5 months. Hassan et al. in 2015 reported a patient's age between 9 months and 7 years [16] which was similar to our data. Ekinci et al. in 2015 [17] reported a patient's age at the time of surgery between 1 and 17 years with a mean age of 4.5 years. Alkan et al. in 2008 [18] reported a mean patient's age at the time of operation of $5.9 \pm 3.1$ years.

So the patient's age in our study was the younger among the above studies (except for Hassan et al. which showed a similar data), and the advantage of early surgical correction is easier postoperative family care with less postoperative psychological disturbance.

Intraoperatively, the tourniquet was applied after penile degloving and not including the skin. Adorisio et al. [19] in 2010 and Türken et al [10] in 1999 reported the use of tourniquet over the skin before penile degloving, and by avoiding the use of tourniquet over the skin, there is less likelihood for the development of skin bruising and edema.

In this study, the length of the urethral tube that mobilized was 3-4 times the distance between the hypospadias meatus and the glans tip, which was necessary to avoid meatal retraction. Awad in 2006 [13] reported that the length of mobilized urethra depends on patient age, i.e., $0.5 \mathrm{~cm}$ for patients aged between 2 and 5 years old, $1 \mathrm{~cm}$ in patients aged 5 to 10 years, and $2.5 \mathrm{~cm}$ for those patients older than 10 years old.

The operative time ranged between 45 and $60 \mathrm{~min}$ with an average of $52.5 \mathrm{~min}$, which was slightly longer than the time mentioned by Awad's study in 2006 [13], which ranged from 30 to $60 \mathrm{~min}$ with a mean of $45 \mathrm{~min}$.

During follow-up, 4 (6\%) patients developed hematoma, treated and resolved by antibiotics and compressive dressing. Six (9.2\%) patients developed minor wound infection, which was resolved by daily dressing and antibiotics. Paparel et al. in 2001 [20] reported four (15\%) cases from a total of 26 cases who developed postoperative bleeding and hematoma, one of them was returned to the theater to control the bleeding. Hassan et al. in 2015 [16] reported three $(10 \%)$ cases from a total of 30 patients who developed a postoperative hematoma, which was treated conservatively and resolved spontaneously. In the same study, two 
(6\%) from a total of 30 patients have experienced wound infection, treated with daily dressing and antibiotics.

So, the incidence of postoperative hematoma in our study was less than what was mentioned in the above studies, but with a slightly higher rate of wound infection, and the reason for that may be due to improper family care at home, as all of these cases were discharged home on the second day postoperatively and followed up at the outpatient clinic.

Regarding late complications, meatal stenosis was reported in $3(4.6 \%)$ patients, who responded well to urethral dilatation on a weekly basis for three successive weeks. Meatal retraction was observed only in one (1.5\%) patient with subcoronal hypospadias, which does not required any further intervention because the neomeatus remained within the limit of the glans, while urethral fistula was not reported in any patient. Awad in 2006 [13] mentioned that only one (1.3\%) patient from a total of 72 patients developed urethral fistula, another one $(1.3 \%)$ also developed meatal retraction, and four (5.5\%) patients complicated by meatal stenosis. Ekinci et al. in 2015 [17] reported four (2\%) patients from a total of 171 patients that developed meatal stenosis, four (2\%) patients developed a fistula, and four (2\%) patients experienced meatal retraction. Hassan et al. [16] reported three (10\%) cases from a total of 30 patients that complained of meatal stenosis. Two (6\%) patients developed meatal retraction, one of them required a redo surgery. Paparel et al. [20] reported five (19.2\%) patients from a total of 26 cases who developed late meatal stenosis, which required a secondary meatotomy.

So, all of the above studies (except in EKinci et al.) had a higher rate of postoperative meatal stenosis if compared with our study, and the reason for that may be due to the use of a ventral midline slit in the mobilized urethra (about 2-3 mm long) for cases which had already stenosed native meatus, in addition; the wide glans wings that were routinely done in our cases is essential to avoid meatal stenosis

Our study's incidence of meatal retraction was nearly similar to the above studies (except in Hassan et al.'s study, which showed a higher incidence by about 3-folds).

The postoperative urethral fistula was not reported in our patients, and if compared with the above studies, our results were better. The reason for that may be due to the exclusion criteria for our patients in which any patient with a hypoplastic urethra was excluded from this study, as the thin urethral tissue may be more venerable to ischemia or even injury during mobilization, which in turn may lead to fistula formation.

\section{Conclusion}

The urethral mobilization technique is a good choice for repairing distal hypospadias especially for boys who are previously circumcised, as the preputial flap is not required in this technique. It provides good cosmetic and functional results, and if a careful patient selection is applied, with the exclusion of boys with a hypoplastic urethra, major complications including urethral fistula and meatal retraction rarely develops.

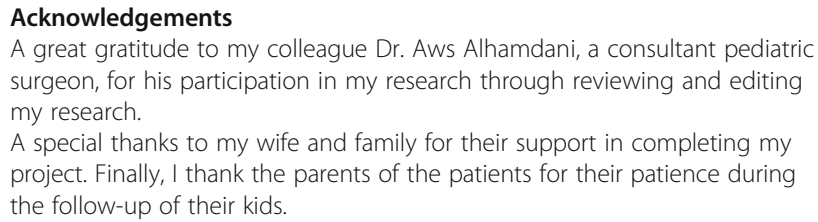

A great gratitude to my colleague Dr. Aws Alhamdani, a consultant pediatric surgeon, for his participation in my research through reviewing and editing my research.

A special thanks to my wife and family for their support in completing my project. Finally, I thank the parents of the patients for their patience during the follow-up of their kids.

\section{Author's contributions}

The author read and approved the final manuscript.

Funding

Not applicable

Availability of data and materials

The data of all studied patients are available to be submitted once required.

\section{Declarations}

Ethics approval and consent to participate

This study has been approved by the Institutional Ethical Committee at the Faculty of Medicine - University of Mosul, and a written informed consent form was taken from the patient's parent to participate in this study after explaining the surgical technique and the aim of the study (Committee's reference number: UOM/COM/MREC/20-21 11

\section{Consent for publication}

A written consent form was obtained from the patient's parent for possible publication.

\section{Competing interests}

The author declares that there are no competing interests.

Received: 4 March 2021 Accepted: 16 August 2021

Published online: 10 November 2021

\section{References}

1. Kalfa N, Philibert P, Baskin LS, Sultan C. Hypospadias: interactions between environment and genetics. Mol Cell Endocrinol. 2011;335(2):89-95. https://doi.org/10.1016/.mce.2011.01.006.

2. Marrocco G, Grammatico P, Vallasciani S, Gulia C, Zangari A, Marrocco F, et al. Environmental, parental and gestational factors that influence the occurrence of hypospadias in male patients. J Pediatr Urol. 2015;11(1):12-9. https://doi.org/10.1016/j.jpurol.2014.10.003.

3. Blaschko SD, Cunha GR, Baskin LS. Molecular mechanisms of external genitalia development. Differentiation. 2012;84(3):261-8. https://doi.org/10.1 016/j.diff.2012.06.003.

4. Bellinger MF. Embyrology of the male external genitalia. Urol Clin North Am 1981:8(3):375-82. https://doi.org/10.1016/50094-0143(21)01293-3.

5. Sommer JT, Stephens FD. Dorsal urethral diverticulum of the fossa navicularis: symptoms, diagnosis and treatment. J Urol. 1980;124(1):94-7. https://doi.org/10.1016/S0022-5347(17)55312-4.

6. Kurzrock EA, Baskin LS, Cunha GR. Ontogeny of the male urethra: theory of endodermal differentiation. Differentiation. 1999;64:115-122. 5.

7. Koff SA. Mobilization of the urethra in the surgical treatment of hypospadias. J Urol. 1981;125(3):394-7. https://doi.org/10.1016/S0022-5347(1 7) $55048-X$.

8. Beck C. A new operation for balanic hypospadias. N Y Med J. 1898;67:147.

9. Atala A. Urethral mobilization and advancement for midshaft to distal hypospadias. J Urol. 2002;168(4 Part 2):1738-41. https://doi.org/10.1016/ 50022-5347(05)64402-3.

10. Türken A, Senocak ME, Büyükpamukçu N, Hiçsönmez A. The use of eccentric circummeatal-based flap with combined limited urethral mobilization 
technique for distal hypospadias repair. Plast Reconstr Surg. 1999;103(2): 525-30. https://doi.org/10.1097/00006534-199902000-00024.

11. Van der Horst HJ, de Wall LL. Hypospadias, all there is to know. Eur J Pediatr. 2017:176(4):435-41. https://doi.org/10.1007/s00431-017-2864-5.

12. Hamdy $\mathrm{H}$, Awadhi MA, Rasromani KH. Urethral mobilization and meatal advancement: a surgical principle in hypospadias repair. Pediatr Surg Int 1999;15(3-4):240-2. https://doi.org/10.1007/s003830050566.

13. Awad MS. Urethral advancement technique for repair of distal penile hypospadias. Indian J Plastic Surg. 2006;39(01):34-8. https://doi.org/10.1055/ s-0039-1700458.

14. McGowan AJ Jr, Waterhouse K. Mobilization of the anterior urethra. Bull NY Acad Med. 1964;40:776-82.

15. Haberlik A, Schmidt B, Uray E, Mayr J. Hypospadias repair using a modification of Beck's operation: followup. J Urol. 1997;157(6):2308-11. https://doi.org/10.1016/50022-5347(01)64771-2.

16. Hassan HS, Almetaher HA, Mohammed N, Elhalaby EA. Urethral mobilization and advancement for distal hypospadias. Ann Pediatr Sur. 2015;11(4):239-43. https:/doi.org/10.1097/01.XPS.0000472853.75905.28.

17. Ekinci S, Çiftçi AÖ, Karnak I, Şenocak ME. Eccentric circummeatal based flap with limited urethral mobilization: an easy technique for distal hypospadias repair. J Pediatr Urol. 2015;2:396-400.

18. Alkan M, Oguzkurt P, Ezer S, Ince E, Hicsonmez A. Evaluation of the results of eccentric circummeatal based flap with combined limited urethral mobilization technique for distal hypospadias repair. J Pediatr Urol. 2008; 4(3):206-9. https://doi.org/10.1016/j.jpurol.2007.11.008.

19. Adorisio O, Elia A, Landi L, Taverna M, Malvasio V, D'Asta F, et al. The importance of patient selection in the treatment of distal hypospadias using modified Koff procedure. J Pediatr Urol. 2010;6(2):139-42. https://doi.org/1 0.1016/j.jpurol.2009.06.015.

20. Paparel P, Mure PY, Garignon C, Mouriquand P. Journal of the French Association of Urology. [Koff's urethral mobilization: report of 26 hypospadias presenting a distal division of the corpus spongiosum]. Society of French Urology. 2001;11:1327-30.

\section{Publisher's Note}

Springer Nature remains neutral with regard to jurisdictional claims in published maps and institutional affiliations.

\section{Submit your manuscript to a SpringerOpen ${ }^{\circ}$ journal and benefit from:}

- Convenient online submission

- Rigorous peer review

- Open access: articles freely available online

- High visibility within the field

- Retaining the copyright to your article

Submit your next manuscript at $\boldsymbol{\nabla}$ springeropen.com 